\title{
2019: A Year of Challenges and Change
}

How to assess global health at the close of 2018 and project achievable goals for the new year? WHO began on a somber and urgent note by identifying Ten Threats to Global Health in 2019. They are: air pollution and climate change; noncommunicable diseases; global influenza pandemic; fragile and vulnerable settings; antimicrobial resistance; Ebola and other high-threat pathogens; weak primary health care; vaccine hesitancy, dengue and HIV. Cuba is vulnerable to many of these threats, but perhaps more importantly, it's already taking them on, proposing more intersectoral actions to address social determinants building upon the country's robust primary health care system.

Esquivel-Lauzurique's Perspective examines how Cuba's primary care network contributes to health outcomes for infants and children through the first two years of life, and analyzes the results according to the recommendations of the 1000 Days indicators. These indicators, developed by the Washington DCbased non-profit, 1000 Days, aim to promote optimal health and development through evidence-based interventions during pregnancy and early childhood.

In this issue we also reprint an article on the "team science" approach to child vaccine R\&D by Dr Nivaldo Linares-Pérez, winner of Cuba's 2018 National Health Prize, the Ministry of Public Health's highest award. While the Pneumococcus Project is certainly not the only effort to use this approach for accelerated vaccine introduction, the experience provides insight into its application in one Cuban setting.

Cuba's health system has also been identified as one of the few offering universal coverage and access-universal health-a topic that for the first time will be the centerpiece of a High-Level Meeting during the UN General Assembly. In part two of our interview with Dr Cristian Morales, former PAHO/WHO Representative in Cuba, he discusses the commitment by the Americas' governments to universal health and proposes strategies for transforming the region's health systems to advance towards this goal. His comments are particularly timely now, when several countries in the Americas Region are suffering greater disparities in health and health care access. In addition, the interview offers a preview of the topic for MEDICC Review's special issue, planned to coincide with this important meeting. Its contents will examine concrete, programmatic contributions to universal health by Cuba's health system and its professionals.

Two articles in the current issue relate to WHO's top ten threats to world health: the first alludes to the significant strides Cuba has made in prevention, management and new treatments for diabetes-which as yet have not been duly reflected in national and international scientific publications. Corrales-Reyes' paper reminds us that workforce strength and public health achievements cannot be assumed to translate automatically into scientific dissemination. He notes that while many Cuban professors and specialists collaborate with other countries, especially in Latin America and Africa, neither have these partnerships yielded a comparable volume of scientific articles. Similarly (as pointed out in a previous Viewpoint), original research on Cuba's experience in primary care is scarcely presented in the peer-reviewed literature. In both cases, one possible contributor is the absence of formal training in scientific writing in the medical curriculum. To help address this training gap, in 2016 MEDICC Review (in conjunction with PAHO and Cuba's National School of Public Health) began offering annual writing courses, with participation by Cuban, US and European experts.

The second article referring to the WHO "top ten" is devoted to Cuba's top researcher in dengue and other arboviruses: virologist Dr Guadalupe Guzmán. She is highlighted as part of MEDICC Review's series Cuba's Women of Science. Among her many accomplishments, Dr Guzmán directs a biannual international course in dengue and arboviral diseases (the next one slated for August 2019). She also directs the WHO/PAHO Collaborating Center for Dengue and its Control and through last year was president of the Arbovirus Diagnosis Laboratory Network of the Americas (RELDA).

Dr Guzmán's work is ever more vital today, when tropical regions worldwide are experiencing a dramatic resurgence in dengue and other arboviral diseases, with more severe forms of dengue recently emerging globally. WHO reports a 30 -fold worldwide increase in dengue over the past five decades. Cuba saw outbreaks in 2018 in the island's central and eastern regions. Dr Guzmán refers to innovations in dengue control and research, and to what she terms the all-important role social scientists are playing in arriving at new, more effective strategies to ensure community participation in dengue control efforts. She reminds readers that the same efforts applied to dengue prevention can also prevent Zika, chikungunya and even yellow fever.

For Cuba, 2019 marks a year of change, as citizens go to the polls on February 24th to vote on a proposed new version of its Constitution, a document that continues to assert, among other articles, the right to free, universal and public health care. At the same time, this year marks the celebration of the 500th anniversary of the Cuban capital, and Havana is expected to receive not only an unprecedented number of visitors but also significant investment, despite a tense economic situation.

At MEDICC Review, we have two important changes to announce. We are pleased to welcome to our editorial team as Senior Editor, English Edition, Dr Elizabeth Vasile, a cultural geographer whose skills will help strengthen MEDICC Review's social science and qualitative research content. At the same time, we are saying farewell to Dr Christina Mills, nine-year veteran as Managing Editor, whose keen scientific judgment and teaching have benefitted us all. She has promised to continue to collaborate with the journal, which pleases us no end. 1 -

\section{The Editors}

